\title{
Assessment of Urban Rooftop Grid Connected Solar Potential in Nepal
}

\author{
Jagan Nath Shrestha ${ }^{1}$, Debendra Bahadur Raut ${ }^{2, *}$ \\ ${ }^{1}$ Center for Energy Studies, Institute of Engineering, Tribhuvan University, Pulchowk, Lalitpur, Nepal \\ ${ }^{2}$ Thapathali Campus, Institute of Engineering, Tribhuvan University, Thapathali, Kathmandu, Nepal \\ Corresponding Email: raut.debendra@tcioe.edu.np
}

\begin{abstract}
:
The power shortage problem faced by Nepal since last two decades is one of the major hurdles for its socio-economic development. At present load shedding is being managed by significant import of electricity from India thus increasing trade deficit of Nepal. The accelerated alternative methods of generation of electricity in Nepal need to be explored. This paper assesses the potential of rooftop solar Photovoltaic (PV) system in residential buildings in their major cities namely Kathmandu valley, Pokhara and Biratnagar of Nepal. The data indicated in this paper are collected from the predefined set of questionnaire and field survey in the randomly sampled households in 2016. Form the quantitative analysis of the data, it is found that the average roof top area available for PV installation in residential buildings are 14.5 sq.m, 12.45 sq.m and 19 sq.m for Kathmandu, Pokhara and Biratnagar cities respectively. Considering 557,027 residential buildings in Kathmandu; 77,523 in Pokhara and 33,075 in Biratnagar, total PV power potential is estimated to be $810 \mathrm{MWp}, 96.5 \mathrm{MWp}$ and $63.5 \mathrm{MWp}$ in respective cities. To estimate the energy potential the annual average peaksun hours considered are 5.54, 5.58 and 5.13 for Kathmandu, Pokhara and Biratnagar city respectively, data taken from Solar and Wind Resource Assessment (SWERA) report. The total power potential in all three cities is found to be $970 \mathrm{MWp}$ which could generate $1,310 \mathrm{GWh}$ that comes out to be $24 \%$ of the electricity sold by Nepal Electricity Authority (NEA) in fiscal year 2017/18. If shade free roof top space available of the $50 \%$ residential buildings are utilized for PV installation (333,762 numbers), about $12 \%$ of the Nepal's utility electricity sold in the fiscal year 2017/18 could be saved annually. The technical barriers for the grid connection of roof top solar is not a major issue now as NEA has set the guidelines for it.
\end{abstract}

Keywords: Rooftop Solar, Residential Power Potential, Grid Connection, Energy Yield

\section{Introduction}

To resolve the existing severe power crisis and enhance energy security by diversifying Nepal's energy mix, abundant solar PV potential need to be harnessed. Therefore, the need for promoting solar PV energy has been rightly emphasized in the recent report by Ministry of Energy, Government of Nepal entitled "National Energy Crisis Mitigation 2016". A study show that about 300,000 residential buildings in Kathmandu valley itself are using battery-inverter backup systems [1] that consume heavily subsidized cheap grid electricity during peak demand times and drastically increases the pressure on national grid, and hence impose more pressure on the current supply system and exacerbates the already severe load shedding.

Although efficiency of electrical inverter backup system is low, users are compelled to use this due to the high initial investment for solar energy. At present, in major cities of Nepal such as the Kathmandu valley, rooftop solar PV systems have not been broadly installed yet either by residential or by commercial and industrial users. Better understanding of the market from the demand, supply, and the regulatory aspects is urgently needed before decisions on proper intervention can be made.

A similar study was carried out in [2] for Kathmandu valley found that average $25 \mathrm{~m}^{2}$ available roof surfaces for PV and about $5 \%$ roof space lies between 50 to 100 $\mathrm{m}^{2}$. But this study was conducted in Kathmandu valley only and didn't estimate the total roof top potential, energy generation potential, critical aspects from financing and suppliers were not conducted in this study.

The overall objective of this paper is to assess the potential of roof top solar PV in major cities of Nepal namely Kathmandu valley, Pokhara and Biratnagar. This paper also explores the barriers to further development of roof top PV and recommends proper interventions required to address the barriers. To meet the principle objectives, analysis was done from the demand, supply, financing, and regulatory point of view. Demand side analysis explored the consumer's electricity consumption pattern and roof top PV installation capacity on residential buildings whereas the supply side accessed 
the key data from the financing institutions, solar manufacturers and suppliers.

\section{Methodology adopted}

Quantitative research methodology is used to analyze the data which is gathered from the structural survey in the targeted area. Five sets of questionnaires were prepared each for the residential, commercial, industrial consumers as well as for the financing institutions and solar PV suppliers.

\subsection{Data collection}

Primary data was collected from baseline survey on demand side, supply side and financial institutions that are financing solar PV business in Nepal. Information collected as part of the baseline survey on demand side includes the demographic and buildings characteristics, current electricity usage pattern, customer awareness and interest, availability of PV modules in the current market, reasons for customer purchase or non-purchase, willingness to pay etc. Survey engineers have visited the buildings and measured the detail parameters including the snaps of sampled of roof top.

Information collected on supply side survey includes the records on supply of PV modules, prices, and market share of the major suppliers, supplier's offer to the consumers in "back-up" mode or only "feed-in" mode, services (pre-and-post sales) provided by supplier, financing methods and terms of conditions, awareness of government subsidy programs, fiscal incentives such as waiving of VAT and import duties, and any regulations on quality assurance and quality control (NEPQA 2015 revised version) standards, major barriers to roof top solar PV installation etc.

Also, secondary data about the utility consumers, total numbers of buildings etc. were collected from the NEA (Nepal Electricity Authority) and Nepal Census Report 2011.

Similarly, meteorological data for the study area were taken from Solar and Wind Energy Resource Assessment (SWERA) report [3]. From Fig. 1, the annual average peak sun hours used to estimate the energy in this study are 5.54, 5.58 and 5.13 for Kathmandu, Pokhara and Biratnagar city respectively.

\subsection{Sampling}

Under the predefined sample size, the random samples were selected based on the economic status, classes and power consumption profile.

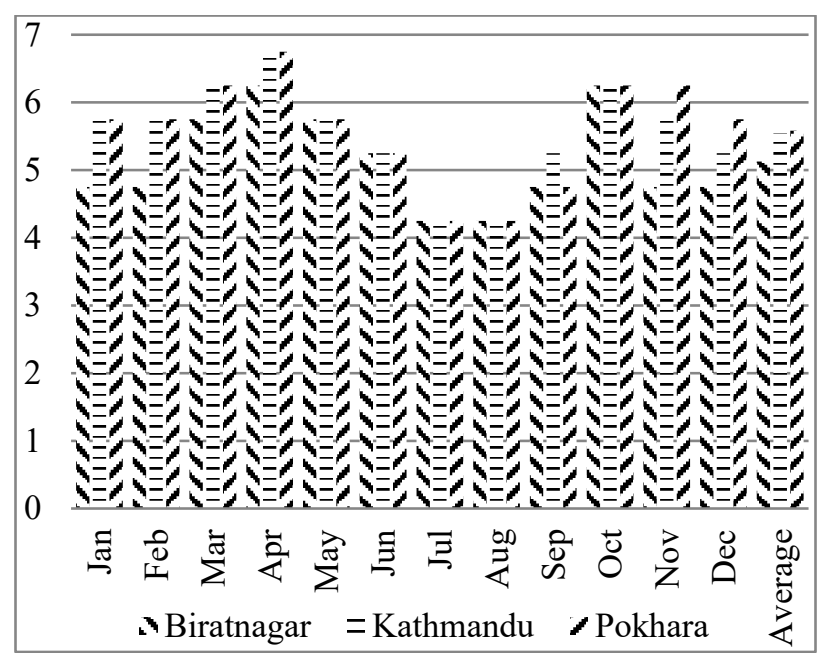

Figure 1: Solar insolation at flat plate tilted to latitude, $\mathrm{kWh} / \mathrm{m}^{2} / \mathrm{day}$

\subsection{Population}

From [4] total numbers of residential buildings are projected to 2015 with growth rates of $6 \%, 12 \%$ and $4 \%$ per year in Kathmandu, Pokhara and Biratnagar cities respectively. Therefore, the total population considered in this study is 557,027; 77,523 and 33,075 for Kathmandu, Pokhara and Biratnagar cities respectively. Residential buildings considered are only cement bonded bricks/stone and with RCC structure only and buildings with mud bonded bricks/stone and wooden pillar are excluded in all the cities.

\subsection{Data analysis}

Statistical analysis tools [5] is used with precision level (e) $= \pm 7 \%$ and $95 \%$ of confidence level and $\mathrm{P}=0.5$. Data collected from residential buildings are classified with the foot print area as small $\left(<100 \mathrm{~m}^{2}\right)$, medium $\left(100 \mathrm{~m}^{2}\right.$ $\left.150 \mathrm{~m}^{2}\right)$ and large $\left(>150 \mathrm{~m}^{2}\right)$. The sample mean and sample standard deviation of each categories area calculated as $\mathbf{E}$ and $\sigma$ respectively. The statistical tools are used to determine the population mean and extrapolate the total roof top solar potential of the whole population.

\subsection{Key assumptions considered to estimate shade free area and $P V$ potential}

The available shade free PV installation roof top area estimation, $\mathrm{kWp}$ potential and final yield from PV estimation are the major technical challenges of roof top PV study. The assumption and steps carried for these key parameters are presented in Fig. 2 and Fig. 3. Consumers are not willing to give all shade free roof top are for PV 
installation because roof top are used for other purposes like drying clothes, social and cultural aspects etc. Therefore, based on the respondent's statements considering all these Nepalese social-cultural aspects, on an average $30 \%$ of the shadow free areas of roof top are considered in this study as available space for PV modules in residential sectors.

Energy calculations for example, in reference to Fig. 3, residential buildings in Katmandu valley will produce $0.67 * 5.54=3.7 \mathrm{kWh} / \mathrm{kWp} /$ day of end use energy however, it may vary as it depends on the efficiency of BOS used in real field project.

\section{Results and discussion}

\subsection{Existing power backup system}

It is quite interesting to know that about $35 \%$ of the residential buildings use solar PV system to power their home during load shedding hours as shown in Fig. 4 (a).
In addition, more than $60 \%$ of residential buildings use less than $100 \mathrm{Wp}$ solar PV system for lighting purpose during the power outages among which the most common size was $20 \mathrm{Wp}$ and $40 \mathrm{Wp}$ PV modules. However, the most common use of inverter in inverterbattery-backup mode were $600 \mathrm{VA}$ to $850 \mathrm{VA}$ for Kathmandu and Pokhara but residences in Biratnagar most commonly (80\%) used $1400 \mathrm{VA}$ to $1500 \mathrm{VA}$ inverter to power all the basic electrical devices with first a priority to lighting and cooling.

In Kathmandu, more than $60 \%$ of the PV backup full hours of load shedding with designed loads and 5\% backups the load shedding hours for less than $50 \%$ of the peak load shedding hours. Also, it is revealed that more than $40 \%$ of the consumers satisfied with their PV systems as shown in Fig. 4(b). Regarding the age of existing PV backup, $22 \%$ of the PV systems in Kathmandu and 33\% in Biratnagar are more than 5 years old and likely to replace the storage battery while in

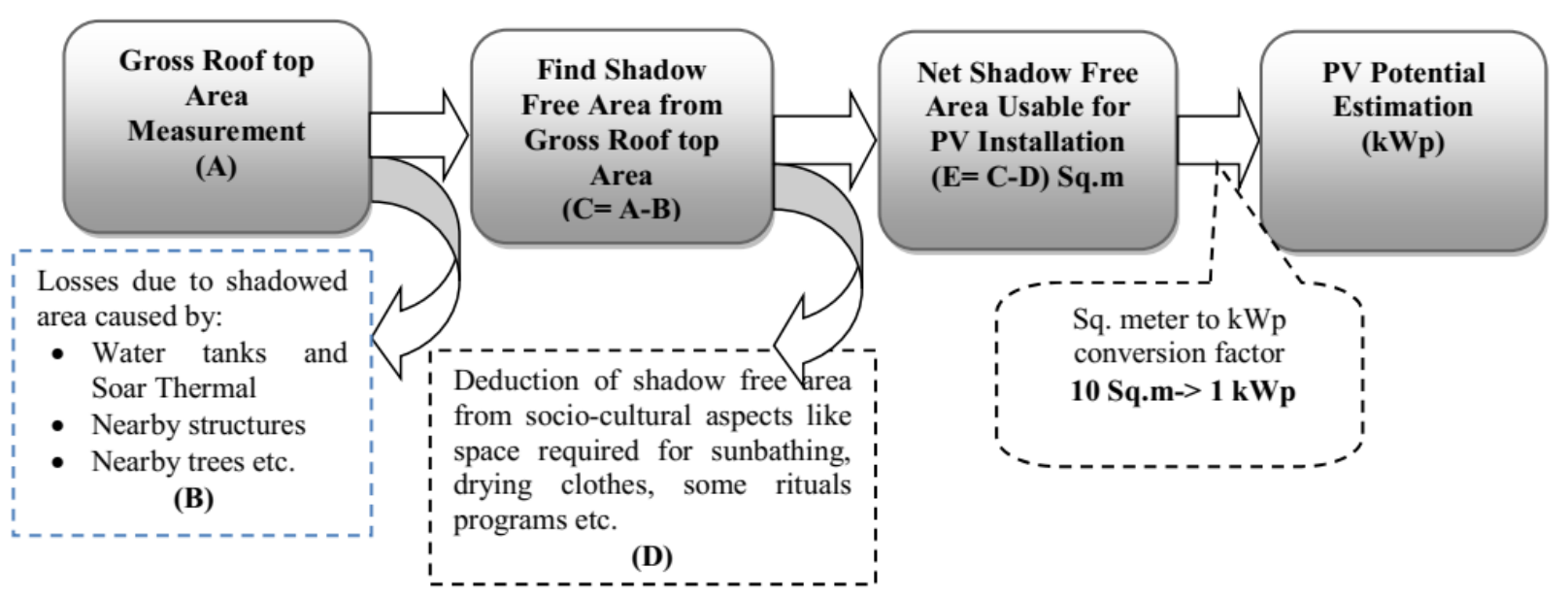

Figure 2: Shadow free area and PV potential estimation steps for residential sectors

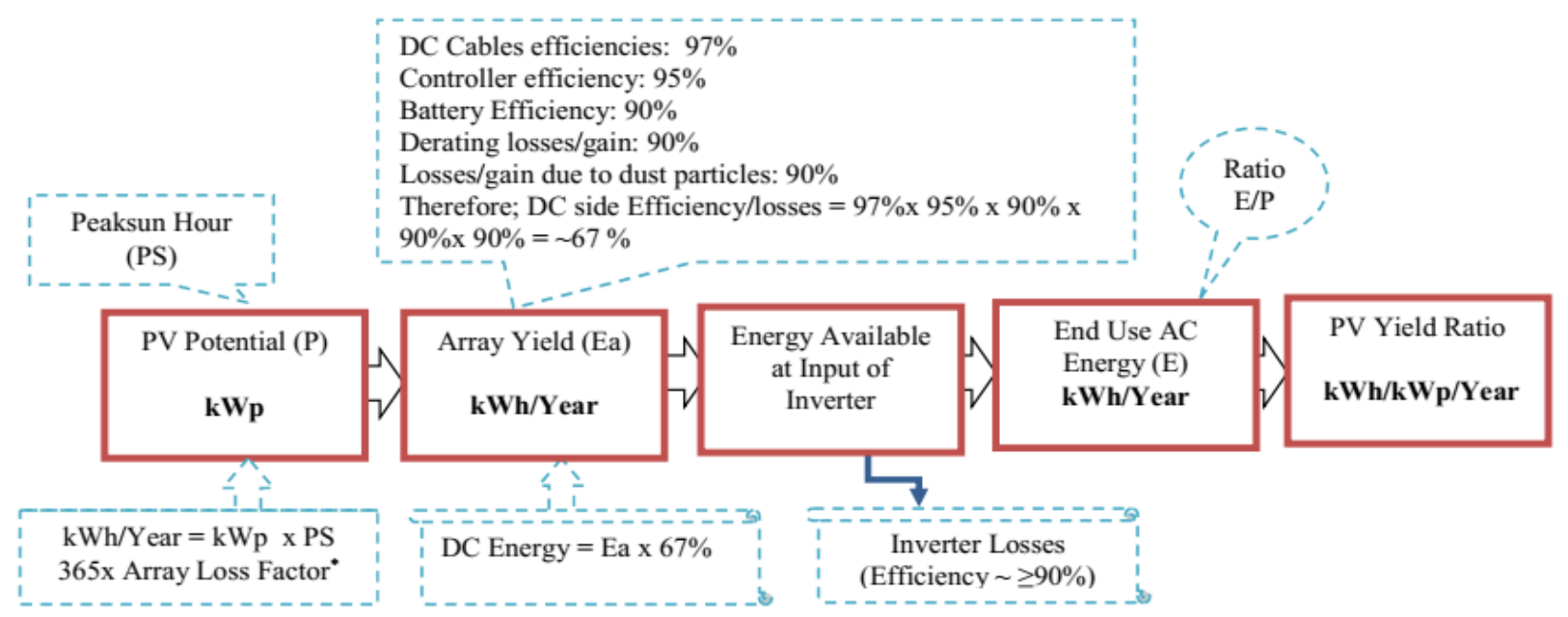

Figure 3: Steps to determine the energy generation potential from PV power capacity potential 


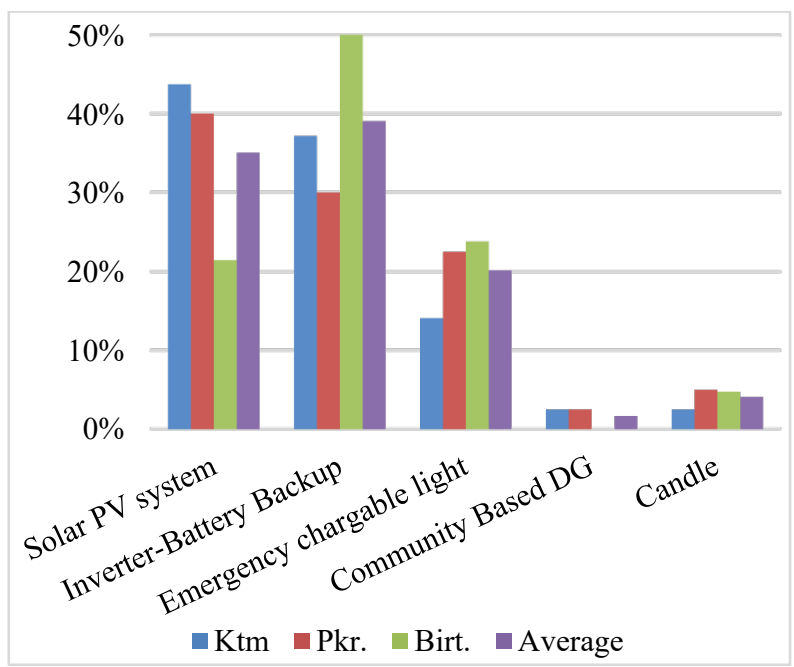

Figure 4 (a): Existing power backup technology used in residential buildings by type

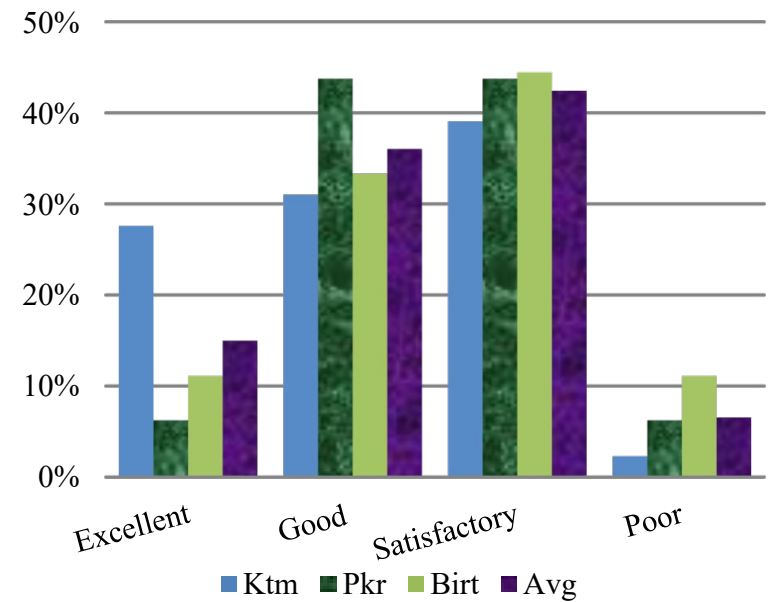

Figure 4 (b): Consumer satisfactions with existing roof top solar

Pokhara, about $70 \%$ of the solar PV system are purchased within last 2 years.

Regarding the source of income, about $80 \%$ of the consumers in Kathmandu purchased their PV system from service income whereas more than two-third of the consumers in Pokhara and Biratnagar city purchased from their business income. It is to be noted that the number of consumers purchasing solar PV systems with subsidy are insignificant. Though government of Nepal provide subsidy for urban roof top solar system since 2015 , it can be said that almost all consumers in three cities purchased their PV systems without subsidy.

\subsection{Existing power consumption profile}

The study revealed that there are more than 200,000 residential buildings in three cities that have $5 \mathrm{~A}$ utility meter and use basic electrical appliances only, also about $19 \%$ residential buildings in Kathmandu, $40 \%$ in
Pokhara and less than $5 \%$ in Biratnagar cities consume less than 80 units per month, which is nominal unit set by NEA.

\subsection{Consumer awareness and major barriers}

Consumer awareness is the major challenge for adopting and promoting urban roof top solar program in Nepal. This study shows that more than $80 \%$ of the respondents either do not know or partly know about the government subsidy via "Urban Solar PV Subsidy Program 2015". This factor clearly indicates that effective awareness campaign is essential immediately. Regarding the awareness of quality assurance, almost all respondents (97\%) are not aware of Renewable Energy Test Station (RETS) and Nepal PV Quality Assurance (NEPQA) standards.

As can be seen from Fig. 5, most of the respondents are very much concerned with the initial cost of PV systems. They also pointed out that after sales service and low battery life are hampering wide spread use of PV systems. Some respondents expressed their opinion that they are unable to use PV systems as they do not have enough sunny space; quality of BOS etc.

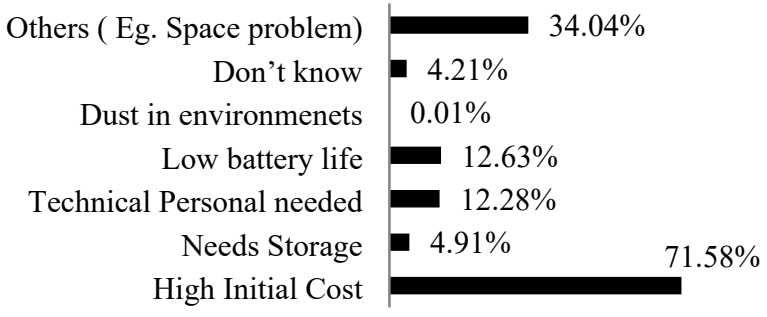

Figure 5: Consumer awareness on major bottleneck to urban solar program in Nepal

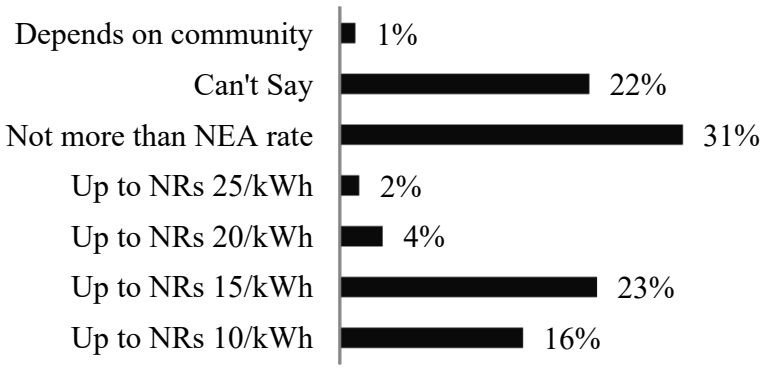

Figure 6: Consumer response on willingness to pay for $24 * 7$-hour available electricity in all cities in residential sectors.

Fig. 6 show that $23 \%$ of the respondents are ready to pay up to Rs. 15/unit should they be provided 24/7 hours reliable electricity by the utility. This is almost two times higher than the average unit cost of electricity in Nepal. 
$31 \%$ of the respondents are ready to pay as per NEA set tariff for $24 / 7$ hours interruptible electricity supply. This clearly indicates the importance of electricity supply in Nepalese society.

\subsection{Roof top PV potential and technical feasibility}

The estimations of roof top potential include following:

- Gross roof top area

- Shade free roof top area

- Area available for PV installation

- Estimated kWp potential

- Estimated energy generation $(\mathrm{kWh} /$ year) potential

It has been observed that Kathmandu valley has diversified roof top size and building height ranging from 4 meter to 20 meters. But in Pokhara city, buildings are uniform in size and height but in Biratnagar, buildings are wider spaced with lower heights.

Statistical data analysis (confidence level of $95 \%$ and $\mathrm{Z}=1.96$ ) shows that the sample mean of gross roof top area of Kathmandu is $80.39 \mathrm{~m}^{2}$ (sampled data varies from $12.55 \mathrm{~m}^{2}$ to $208 \mathrm{~m}^{2}$ ), it is 72.48 (sample variation $9.29 \mathrm{~m}^{2}$ to $335 \mathrm{~m}^{2}$ ) for Pokhara and $116.83 \mathrm{~m}^{2}$ (samples from 40 $\mathrm{m}^{2}$ to $552 \mathrm{~m}^{2}$ ). From this scenario, the population mean is $76.21 \mathrm{~m}^{2}, 51.25 \mathrm{~m}^{2}$ and $91 \mathrm{~m}^{2}$ for three respective cities with all average of $\mathbf{7 2 . 6 6} \mathbf{~ m}^{\mathbf{2}}$ of gross roof top area of residential buildings from all cities. From Table 2, it can be concluded that every residential building has $\sim 15 \mathrm{~m}^{2}$ area available for PV modules. In summary, $72.66 \mathrm{~m}^{2}$ is the gross roof top area, $51.32 \mathrm{~m}^{2}$ is the shadow free area and $15.39 \mathrm{~m}^{2}$ is the roof top area available for PV installation in all cities with total PV potential of 810 MWp, $96 \mathrm{MWp}$ and $63 \mathrm{MWp}$ in respective cities.

According the methodology presented in this report, the calculated annual energy potential (GWh/year) from roof top of residential buildings are 1097, 131 and 79 for respective cities $1308 \mathrm{GWh}$ which is about $24 \%$ of the total utility energy sold which is $5526.12 \mathrm{GWh}$ [6] for the country in the fiscal year $2017 / 18$ and $50 \%$ of the

Table 1: Summary of roof top PV potential in residential sectors

\begin{tabular}{|l|l|l|l|}
\hline Measuring Parameters & Ktm & Pkr & Birt \\
\hline Total gross roof top area $\left(\mathrm{km}^{2}\right)$ & 42.45 & 3.97 & 3 \\
\hline $\begin{array}{l}\text { Total area available for PV Installation } \\
\left(\mathrm{km}^{2}\right)\end{array}$ & 8.10 & 0.97 & 0.64 \\
\hline Average gross roof top area $\left(\mathrm{m}^{2} /\right.$ building $)$ & 76.21 & 51.25 & 91 \\
\hline $\begin{array}{l}\text { Average shade free roof top area } \\
\left(\mathrm{m}^{2} / \text { building }\right)\end{array}$ & 48.48 & 41.5 & 64.0 \\
\hline $\begin{array}{l}\text { Average area available for PV installation } \\
\left(\mathrm{m}^{2} / \text { building }\right)\end{array}$ & 14.54 & 12.45 & 19.2 \\
\hline $\begin{array}{l}\text { Average PV potential } \\
(\mathrm{kWp} / \text { building })\end{array}$ & 1.45 & 1.24 & 1.92 \\
\hline Total estimated PV potential (MWp) & 810 & 96 & 63 \\
\hline
\end{tabular}

Table 2: Energy consumption patterns of residential building Vs roof top shade free area

\begin{tabular}{|c|c|c|c|c|c|}
\hline Building Class & \begin{tabular}{|l|} 
Total \\
Building
\end{tabular} & $\begin{array}{l}\text { Average Annual Energy } \\
\text { Consumption }\end{array}$ & \begin{tabular}{|l|} 
Day Time Energy \\
Demand Potential (Max)
\end{tabular} & \begin{tabular}{|l|} 
Dark Hour Energy \\
Demand Potential (Max)
\end{tabular} & \begin{tabular}{|l} 
Total Connected \\
Load
\end{tabular} \\
\hline $\begin{array}{l}\text { Shade free roof } \\
\text { top area }\left(\mathrm{m}^{2}\right)\end{array}$ & $(\%)$ & $\mathrm{kWh} /$ year/building & $\mathrm{kWh} /$ day & & $\mathrm{kW} /$ building \\
\hline \multicolumn{6}{|c|}{ Kathmandu City } \\
\hline Small $(<20)$ & $33.51 \%$ & 1,956 & 2.91 & 5.03 & 3.19 \\
\hline Medium (20-40) & $55.67 \%$ & 2,256 & 2.72 & 5.21 & 3.48 \\
\hline Large $(>40)$ & $10.82 \%$ & 3,287 & 5.95 & 6.43 & 4.52 \\
\hline \multicolumn{2}{|c|}{ All Buildings (Average) } & 2,267 & 3.13 & 5.28 & 3.49 \\
\hline \multicolumn{6}{|c|}{ Pokhara City } \\
\hline Small $(<20)$ & $66.67 \%$ & 1,612 & 1.72 & 4.19 & 2.06 \\
\hline Medium (20-40) & $14.29 \%$ & 2,505 & 5.90 & 11.69 & 4.38 \\
\hline Large $(>40)$ & $19.05 \%$ & 1,649 & 3.72 & 12.48 & 3.95 \\
\hline \multicolumn{2}{|c|}{ All Buildings (Average) } & 1,747 & 2.69 & 6.84 & 2.75 \\
\hline \multicolumn{6}{|c|}{ Biratnagar City } \\
\hline Small $(<20)$ & $19.05 \%$ & 2,171 & 3.59 & 9.63 & 3.23 \\
\hline Medium (20-40) & $19.05 \%$ & 2,171 & 3.59 & 9.63 & 3.23 \\
\hline Large $(>40)$ & $64.29 \%$ & 3,844 & 8.65 & 16.11 & 4.91 \\
\hline \multicolumn{2}{|c|}{ All Buildings (Average) } & 3654 & 7 & 15 & 5 \\
\hline
\end{tabular}


imported electrical energy in the same year. The imported electrical energy in fiscal year is about 2582 GWh [6].

\subsection{Supply side and regulatory side assessment of rooftop PV market}

Supply side assessment covers the supply chain of solar PV modules in the market, supply of solar PV system in different modes, financing options by the suppliers, major barriers on adopting roof top urban solar program by supplier's point of view etc. In the present market context of Nepal, almost $70 \%$ of the PV modules are imported from China. There is a small PV market share of other countries namely Korea, Japan, USA etc in Nepal as shown in Fig. 7.

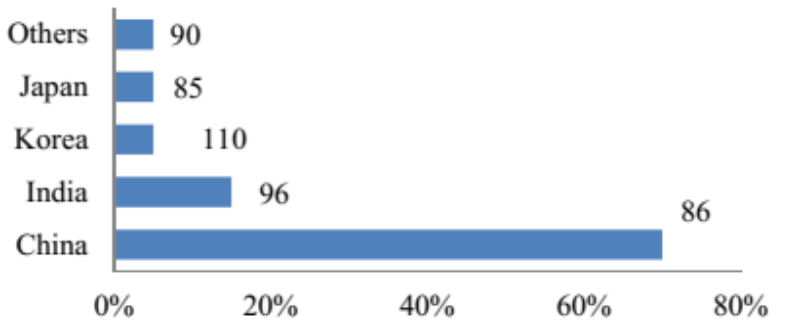

Figure 7: Imported PV modules by country of origin and average wholesale price (NRs/Wp)

Taking about the strength and services provided by PV suppliers in Nepalese market, $50 \%$ of them provide free of cost site survey and energy audit service to the consumers. Also, $80 \%$ suppliers provide free of cost after sales service up to 2 years, $10 \%$ for 1 year and another $10 \%$ for 3 years. $90 \%$ suppliers have their own in-house team for operation and maintenance, the technical personnel ranges from 2 people to 12 people in each company.

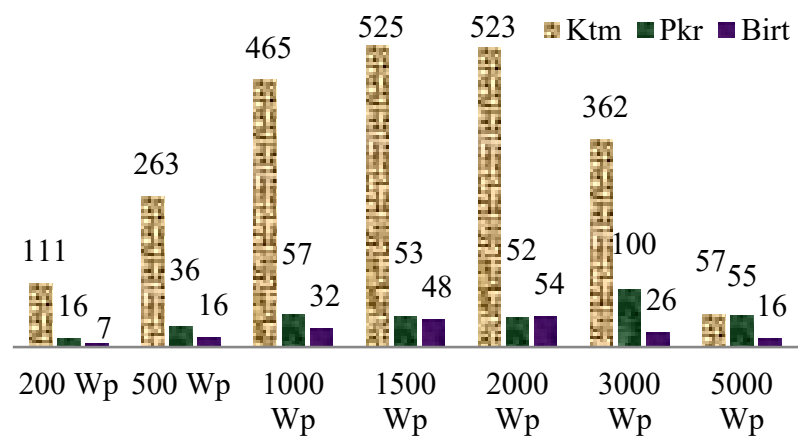

Figure 8: $P V$ potential in MWp with different system size in three cities

Financing mechanism is another important aspect of roof top solar market development. There are five commercial banks authorized to finance under the government subsidy program in Nepal. Out of five listed banks, only one bank has more than 7 years of experience on solar lending. Without subsidy, it has been charging $12 \%$ per annum interest on solar lending but under the subsidy program, all bank lending at $2.25 \%$ per annum interest rates on residential use and $4.5 \%$ per annum on institutional use considering the proposed solar PV system itself as a collateral and validity of loan is 5 years i.e. 60 EMI.

\subsection{NEA Requirements for Grid Connection}

Following minimal criteria is set by NEA for grid connected solar PV (PVGC) system which is approved by NEA Board on 2074/01/13 (April 26, 2017)

- Frequency: $50 \mathrm{~Hz}$

- Voltage Level: $230 \mathrm{~V} / 400 \mathrm{~V} / 11 \mathrm{kV} \pm 5 \%$

- Voltage Waveform: Sinusoidal

- Phase Voltage Imbalance in case of Three Phase System: 1\% (maximum)

- Harmonic Distortion (THD): $<=3 \%$

- Power Factor in between: 0.85 Lag and 0.95 Lead

- Energy to be injected to Grid: Not more than $90 \%$ of Energy consumed from NEA

- Energy Meter: Bi-directional (Grid Side), Solar Generator Meter (PV Generator Side)

- Power Level Injection: $500 \mathrm{Wp}$ min to up to $5 \mathrm{kWp}$ at $230 \mathrm{~V}$ level; more than $5 \mathrm{kWp}$ to up to $40 \mathrm{kWp}$ at $400 \mathrm{~V}$ level; more than $40 \mathrm{kWp}$ at $11 \mathrm{kV}$ level

\section{Conclusion}

The gross roof top area of each residential building was found to be $76 \mathrm{~m}^{2}, 51 \mathrm{~m}^{2}$ and $91 \mathrm{~m}^{2}$ in Kathmandu, Pokhara and Biratnagar cities respectively totaling 49.42 $\mathrm{km}^{2}$ in all cities. After deducting the sunny roof top space to be used for other purpose, the net area for PV installation comes to be $9.71 \mathrm{~km}^{2}$ ( $\sim 20 \%$ of gross roof top area). Total PV potential is $970 \mathrm{MWp}$ out of which $810 \mathrm{MWp}$ available in Kathmandu Valley alone. If all the residential buildings totaling 667,525 numbers in three cities are installed with a roof top PV system in their sunny space, $24 \%$ of the NEA electric energy sold in fiscal year 2017/18 could be saved annually. In addition, the estimated rooftop PV potential could save $50 \%$ of the electric energy imported from India in fiscal year $2017 / 18$.

There is a good market potential of roof top solar in Nepal as NEA has already set the guidelines for net metering system for residential buildings and there is no load shedding in the [6] day time in major cities. 
However, a clear financing mechanism and implementation modality are the major challenges for the promotion of rooftop grid connected solar system in Nepal.

\section{Acknowledgments}

This is a part of the study supported by AEPC. The authors wish to acknowledge the following for their valuable contributions in this study: Dr. Shree Raj Shakya, Dr. Mangala Shrestha, AEPC officials Mr. R. P. Dhital, Mr. S. Gautam, Mr. M. Ghimire, Mr. J. K. Mallik; Students from Acme and Khowpa engineering college: Mr. B. Adhikari, Ms. S. Regmi, Mr. B. Thapa, Mr. P. Amagain, Mr. M. Niraula and Mr. M. Humagain.

\section{References}

[1] S. Nepal, "Freeing the grid connected solar PV system for kathmandu," Kathmandu, 2014.

[2] D. Chianese and J. S. et.all., "Feasibility study on grid connected PV system in Nepal," SUPSI, Kathmandu, 2009.

[3] C. Schillings, R. Meyer and F. Trieb, "High Resolution Solar Radiation Assessment for Nepal," Solar and Wind Energy Resource Assessment (SWERA) (http://swera.unep.net), 2004.

[4] CBS, "National population and housing sensus 2011," NPHC, Kathmandu, 2011.

[5] G. Isreal, Determining sample size, Gainesville: University of Florid, Institute of Food and Agriculture Science (IFAS).

[6] NEA, "A year in Review fiscal year-2017/18," NEA, Kathmandu, August 2018.

[7] Nakarmi, "Policy need for development of rooftop solar PV system in urban areas of Nepal," in Center for Energy Studies, Institute of Engineering, TU, Lalitpur, 2014.

[8] G. Pokharel, "Renewable energy, energy mix and energy security in Nepal," in Institute of Engineering, TU, Thapathali, 2016.

[9] TERAI, "Reaching the sun with rooftop solar," in TERAI, New Delhi, 2014.

[10] D. o. Industry, "Industrial statistics of," FY 2069/70, 2014. 